\title{
Moe fenomen
}

\section{Ines Piibeleht}

"Suurte ajalooliste aegruumide jooksul muutub koos inimkollektiivide kogu eksistentsiviisiga ka nende meelelise taju laad ja viis,” kirjutas Walter Benjamin essees „Kunstiteos oma tehnilise reprodutseeritavuse ajastul" ja lisas, et need meelelise taju muutused on loomulikud, kuid tingitud ka ajalooliselt (Benjamin 2010: 118). Nii võib öelda, et ka "moodsat” on läbi aegade tajutud erinevalt, kuid sellest hoolimata võime rääkida moest kui nähtusest üldisemalt, moest kui fenomenist. Siinses artiklis ei ole kesksel kohal püüdlus defineerida, mis on mood, vaid küsimus, kuidas me saame avada moe kogemust. Huvi moe vastu on eri distsipliinides alates 20. sajandi viimasest veerandist, eriti pärast „kultuurilist pööret” (vt Tamm 2008: 581) märgatavalt kasvanud. Moodi on hakatud käsitlema eri kontekstides, mis omakorda mõjutavad tähenduse variatsioone, näiteks mood kui sotsiaalne nähtus, mood kui märgisüsteem, mood kui kunst, mood kui müüt, mood kui moetööstuse produkt. Moe kui kultuuriliselt kodeeritud objekti tähenduse määratlemine on seotud sellega, millisest kultuurikontseptsioonist lähtutakse ning millist kultuuri kontseptualiseerimise strateegiat kasutatakse. Tänapäeva humanitaarteadustes ei ole vaatamata suurele huvile kultuurinähtuste analüüsi vastu võimalik viidata ühelegi üldaktsepteeritavale strateegiale (Viik 2008: 612). Traditsiooniline moeajalugu lähtus historistlikust strateegiast; moe kui kultuurilise nähtuse tähendust (Burke 2006: 214) on võimalik uurida lähtudes erinevatest epistemoloogilistest strateegiatest.

Kui määratleme kultuuri indiviidi kogemusaktide kaudu, siis lähtume fenomenoloogilisest strateegiast, s.t lähtume maailmast sellisena, nagu see meile on antud meie teadvuses. Fenomenid on „asjad” sellistena, nagu me neid oma teadvuses tajume, mitte sellistena, nagu need on meie kogemusest sõltumatult. Moe kogemuse analüüsimisega seonduv metodoloogilist laadi problemaatika kerkis empiirilisel materjalil põhineva uurimuse ettevalmistamisel, kus moe kogemuse analüüsimiseks on valitud Edmund Husserli välja töötatud fenomenoloogiline meetod, mis keskendub meie teadvuse kogemuses olevate asjade uurimisele. Kogemusakt saab sisu selle akti tähenduse kaudu. Moe kogemuse sisu ja tähendust saab tõlgendada ka kasutades strukturalistlikke meetodeid, mida on rakendatud tunduvalt rohkem kui fenomenoloogilisi. Mille poolest moe uurimine eri meetodeid kasutades erineb, mida ühe või teise meetodiga saab esile tuua ja mida mitte? Järgnev kirjutis keskendub fenomenoloogilise meetodi võimaluste avamisele moe kogemuse analüüsil ja võrdlusele teistel strateegiatel baseeruvate meetoditega.

Nagu juba mainitud, on mõiste mood tähendus ajaloos varieerunud, sest mood on muutunud läbi sotsiaalse struktuuri muutuste ja koos kultuuri arenguga. Sõltumata hoiakust, huvist või huvi puudumisest on mood tähenduslik mõiste kõigile kultuurikogukonna liikmetele, väljendades eelkõige kaasaegsust. Moodsuse mõõtme avaldumist võib kultuuris analüü- 
sida väga erinevate objektide kaudu, seejuures ka üldistades, näiteks teaduse ja kunsti mood. Mõiste mood avarale tähendusväljale vaatamata peetakse esmasena silmas rõivamoodi. On omaette huvitav küsimus, miks. Ajalooline selgitus oleks, et mõisteid mood ja riided on kasutatud sageli sünonüümselt, mis seostabki moe tavatähenduse eelkõige riietusega. Et mõistet piiritleda, jään siinses artiklis moest kui kogemuse objektist rääkides rõivamoe juurde (seegi on väga laia areaaliga piiritlemine, hõlmates disainereid, tooteid, sihtgruppe, esitlemist jms ajaloost kuni tänase päevani), sest see on esmane tähendus ka teoreetilistes käsitlustes. Näiteks Immanuel Kant tõi oma filosoofilises antropoloogias moodi käsitledes esile, et inimene kaldub riietuse valikul matkima „paremaid” (Gronow 2001: 89). Üks esimesi moeteoreetikuid Georg Simmel seostas moodi - riietust - naiste sotsiaalse positsiooniga (Simmel 1904, vt ka Simmel 2006). Nüüdisaegse moeteoreetiku Yuniya Kawamura arvates kasutab aga mood riietust kui „sümboolset esitust” (Kawamura 2005).

Et eristada kogemist kogemuse objektist, kasutan mõistet moodsus, mis viitab (moodsate) objektide tajumisele. Arendades edasi Franz Brentano intentsionaalsuse mõistet, kirjeldas Husserl selle abil teadvuse suunatust objektile. Teadvus on alati teadvus millestki, kusjuures see, millena objekti kogetakse, ei ole objekti omadus, vaid tähendust andev tegevus. Husserli fenomenoloogilisest meetodist lähtuvalt (Husserl käsitleb tähendusloome akte, mis toimuvad tänu erinevatele horisontidele) võib üldistada: nähtused on meile antud nii, nagu me näeme, sest teadvuses olevad tähendushorisondid osalevad reaalsuse ja tähenduse konstitueerimises, seega on moodsus määratletav kui tajuhorisont (Husserl 1993b: 379 jj). Maailm, mida Husserl käsitleb avalduvana „loomulikus hoiakus” (sks k natürliche Einstellung), on selline, mille leiame eest vahetult vaadeldavana. Saame maailma tajuda luues seoseid kahekülgselt lõppematu ajahorisondi kaudu (tajumishetke aktuaalse tähenduse ja ajas kujunenud kogemussisu kaudu), ringi vaadates näeme „rohkem” lähtuvalt kujutlusest. Maailm ei ole ainult asjade maailm, vaid ka väärtuste ja omaduste maailm. Aktuaalselt tajutav on kantud mitte kunagi täielikult määratletud horisontidest (Husserl 1993a: 56-58). Objektid, mida me tähenduslikena näeme, on meie teadvuse fenomenid.

Moega puutume me vahetult kokku pidevalt. Üldistavalt võib öelda, et mood nähtub meile nii igapäevaselt ringi liikudes kui ka erinevatel üritustel, igas tänavapildis ning pildiliselt televisiooni (nt Fashion TV) ja interneti kaudu. Praktiliselt puutub iga inimene iga päev kokku erinevate küsimustega, mis on seotud moega, alates sellest, mida selga panna. Need otsused ei pea loomulikult olema tehtud lähtuvalt moest, ent mood mõjutab siin mõneti paratamatult - näiteks sõltub paljudes kauplustes müügil olev valik hetketrendidest. Meid ümbritsev meediaruum on samuti moega seonduvast temaatikast tulvil. Moega otseselt seonduvad verbaalsed tekstid on tänapäeval enamasti reklaamtekstid, kusjuures reklaam võib olla nii otsene kui ka varjatud. Kui Stephane Mallarmé toimetas 19. sajandi viimasel veerandil moeajakirja La Derniere Mode, siis avaldas ta eelkõige imetlust ilusa suhtes. Praegused ajakirjad on 
osa moe süsteemist, mida juhivad tu ru huvid. Moe teemat kajastav meedia on väga laialdane ja väljaanded erinevad nii oma taseme kui ka võimaluste poolest, ent massidele suunatud temaatika on suhteliselt sarnane ja lihtsakoeline: muutused, uuenemine, ilu, detailide kirjeldused, kaasaegne stiil jms. Meedia mängib tähendustel, mille on meie teadvuses loonud tähendushorisondid - mis ise jäävad konkreetse kogemuse sees küll nähtamatuks. Kuulsamate moeajakirjade kohta on kirjutatud uurimusi, näiteks on käsitletud nende kaudu moe tähendust eri kultuurikeskkondades. Üks selline uurimus keskendub Venemaal, Prantsusmaal ja Suurbritannias ilmuva moeajakirja Vogue erinevale fotode valikule (Kopnina 2007). Moe kogemist mõjutab minu arvates eriti visuaalne külg, seega on moefotol moe kogemuse kujundamisel oluline roll. Seejuures ei eristu moefoto muude fotode hulgast mitte ainult selle tõttu, millise disaineri looming seal on kujutatud, vaid sellele žanrile omaste võtete, näiteks teatava teatraalsuse poolest. Olulised on ka autor, avaldamise koht ja kommenteeriv tekst (Flusser 1984). Võimalik, et ajalooliselt on fotograafia leiutamine moe arengus samalaadne faktor nagu trükikunsti leiutamine kirjanduse arengus. Huvitav on siinkohal fakt, et esimene fotonäitus ja moedemonstratsioon toimusid samas kohas ja peaaegu samal ajal: Pariisis 1855. ja 1858. aastal.

Meedia apelleerib inimese eelhoiakule, et mood tähendab midagi positiivset ja olulist, näiteks loob imagot. Eelhoiakut ennast reklaam ei vormi, see on eelnevalt olemas (positiivse) tähenduse kaudu, mis toetub omakorda millelegi mastaapsemale, näiteks usule progressi. Seda toetab tehnika pidev uuenemine, eriti infotehnoloogia jõuline arenemine.

Moekogemus ei ole midagi staatilist, vaid on pidev protsess. Toetudes Husserlile, saame (eristades asja ilmnemise viisi ilmnevast asjast) keskenduda sellele, kuidas moepilt meile ilmneb, ning kirjeldada, kuidas toimuvad kogemuse aktis akti sisu muutused. Kogemussisu muutudes vaade muutub ja mõjutab järgnevat kogemist. Kõik intentsionaalsed objektid, millele meie teadvus on suunatud, vormuvad nende kogemise käigus. Me kogeme objekte ja näeme nende objektide vormi ja seost ajastule iseloomuliku kujunduse, keelekasutuse või mis tahes muu taustaga. Moeteadlikkus areneb kogemuse käigus, mõjutades samas ka kogemuse sisu. Kogemusakt saab sisu tähenduse kaudu, ent kogemust võimaldavad teadvusstruktuurid ei avaldu konkreetse kogemussisu kaudu. Kui inimene oma kogemust kirjeldab, siis kirjeldab ta ilmnevat asja nii, nagu see talle paistab. Lausetes, mida inimene ütleb, väljendub tema hoiak, näiteks „see ülikond on ajast ja arust”, „mulle meeldib, kuidas praegu salle kantakse”, „see tüüp on küll maalt”, „eriti cool tüüp” jpt. Hoiakud võivad olla erinevad, ent nende tõlgendamise kaudu ilmneb, et mood on tähenduslik mõiste kõigile kultuurikollektiivi liikmetele, olles seega intersubjektiivne (Husserl 1993a: 60). Intersubjektiivsed sümbo/süsteemid, millele keskendub Tõnu Viik, eelnevad konkreetsetele kogemustele ning annavad konkreetse kogemuse käigus loodud mõttele vormi (vt Viik 2008: 608).

Intersubjektiivse sümbolsüsteemina on mood samamoodi uuritav nagu näiteks keel koos professionaalse jm subkultuurilise sõnavaraga, kollektiivset mälu moodustavad narratiivid ja 
kultuse objektid, erinevate tegevuste žanrireeglid, ideoloogiad, müüdid jne. Kui käsitleda kultuuri intersubjektiivset tähendust kandvate väljendusvormide kaudu, siis lähtume kultuuri kontseptualiseerimise väljendusvormilisest strateegiast, mida kasutatakse semiootikas. Kultuurisemiootika määratleb kultuuri kommunikatsiooniakte võimaldavate semiootiliste struktuuride kogumina (Lotman 1999). Mood toimib kommunikatiivselt mittesõnaliste märkide vahendusel, mis edastavad teavet indiviidi sotsiaalse positsiooni, päritolu, elukutse, trenditeadlikkuse, maitse vms kohta.

Üldises plaanis on iga riietus või ruum märgiline. Aastal 1967 ilmunud Roland Barthes'i „Moe süsteem" ei räägi niivõrd moest kui just märkidest, eelkõige detailide tähendusest (Barthes 1990). Barthes'i seisukohti on järgnevates semiootilist laadi moekäsitlustes väga palju kommenteeritud, kritiseeritud ja edasi arendatud. Näiteks on kasutatud sarnaselt Barthes'iga moe süsteemi selgitamiseks paralleelide loomist lingvistiliste süsteemidega (Lurie 1983). Kuigi Barthes'ile on sageli ette heidetud, et ta tõlgendab märke liiga kitsalt, juhib ta Prudence Blacki arvates siiski tähelepanu olulisele, sest "see, kuidas me mõtleme moest, ei ole kogu süsteemi hoomamise tasand, vaid meie kogemus ja reageering detailidele" (Black 2009: 501). Ajaloolisest taustast lähtudes on uuritud märkide tähendust konkreetses kultuuriruumis (Polhemus 1996), kus mood on vaadeldav ühe tekstina laiemas kontekstis.

Mida kujutab endast mood kui tekst? Igapäevaelu tasandil (tänaval, kinos, kohvikus) avaneb iga hetk meie silmade ees märkide paraad. See, mida ja kuidas kantakse, on märgiline ja edastab sõnumit (Lotman 2003: 74-80, Lotman 1999: 241-248), samuti on märgilisus paljudes väljendites, näiteks Pariisi mood viitab erilisele elegantsusele ja ajaloole. Märkide tähendused on tõlgendatavad lähtuvalt retseptsioonist, s.t tähendused varieeruvad lähtuvalt sõnumi edastajast ja vastuvõtjast. Kes koode tunneb, saab nendega ka mängida. Üksteisele mittemõistetavaid koode võivad kasutada eri vanusegrupid või eri elualade esindajad, näiteks ei pruugi arvutispetsialist tabada ülikonna spetsiifilist stiili. Ent üldiselt on need märgid mõistetavad, sest sõnumi kodeerimiseks kasutatavad keeled on kultuurikollektiivis üldmõistetavad, kui ka kõik sõnumid ei ole kõigile ühtmoodi kodeeritavad. Märkide tähendussüsteeme strukturalistlikult analüüsides saame esile tuua teksti kui struktuuri tähendused, mis on modelleeritud mitmete koodisüsteemide poolt. Näiteks märge kutsel: dark suit või smart casual. Mõlemad viitavad stiilile, ent seegi, stiili märkimine on omaette märk traditsioonist. Näiteks smart casual on märk, mis on seotud moega nii laiemas kui ka kitsamas tähenduses - see stiil on alguse saanud alles 1970. aastatel koos Silicon Valley California infotehnoloogiakeskuse arenemisega ja esindab nüüdisaega üldisemalt. Mood kui tekst seob kokku pildid, mis avanevad meie nägemismeelele. Sellest omakorda sõltub märkide tähenduste tõlgendamine.

Moe kui kultuuriliselt kodeeritud objekti tähendust on võimalik tôlgendada, kui keskenduda teadvuse struktuurile. Käsitledes moodi sekundaarse modelleeriva süsteemina struktu- 
ralistliku meetodi abil, on võimalik eristada, milliste tähenduslike koodide kaudu mood kui objekt meie teadvusele mõjub ja kuidas me seda tõlgendame. Sõnumi väljatoomiseks on vajalik analüüsida modelleerimiseks kasutatavat keelt. Kõrvalepõikena: Clifford Geertzi antropoloogilise meetodi abil mingit piiritletud perioodi kirjeldades saab samuti esile tuua kontseptuaalsed struktuurid, mis subjekti mõtlemist mõjutavad (Geertz 1990). Erinevate kollektiivsete praktikate käigus on tähendused institutsionaliseerunud ja intersubjektiveerunud. Vaated moele on neist struktuuridest kantud, meile tundub, et nii „tegelikult” ongi. Moe uurimisel sarnaneb Geertzi meetod Lotmani kultuurisemiootilise meetodiga selle poolest, et fookuses on tähendusstruktuuride väljatoomine. Kultuurisotsioloogiliselt uurides võtaksime arvesse moe kultuurilist vahendatust, eeldusel, et on sellised erilised kultuurilised struktuurid, mis meile tähendust vahendavad, s.t kõik intersubjektiivsed sümbolsüsteemid on sootsiumi kultuurilise arengu ajalooline produkt, sümbolid on kujundatud ajas ja ruumis. Arvan, et moes ei ole väga tugevaid üldkehtivaid sümboleid (võib-olla moodsa arhitektuuri näidised - Jumeirah Emirate Towers vms - on üldmõistetavad kui „moodsuse” monumendid), vaid pigem on eri kultuurikollektiivides välja kujunenud omad sümbolid: Eesti kontekstis näiteks vabariigi presidendi vastuvõtt vabariigi aastapäeval 24. veebruaril ehk niinimetatud pingviinide paraad, Euroopa mastaabis Chaneli kostüümid. Kõige suuremat sümboolset tähendust omab mõiste mood ise. Kui mõistet moodne kasutatakse konkreetsetest riideesemetest rääkides, siis antakse hinnanguid materiaalsetele objektidele, paralleelselt on kasutusel mõisted trendikas või stiilne, millel on suhtes ajaga erinev sisu: trendid vahelduvad kiiresti, stiil on hetkemoe seisukohast ajatu (stiili saab hinnata näiteks terviklikkuse seisukohalt, samuti võib üldistades esile tuua ajastu stiili). Hinnangus avalduvad hindaja trenditeadlikkus ja stiilitaju, mis kujunevad lähtuvalt sellest, kas mood mis tahes mõõtmes - uudsus, eristumine, sõnumi edastamine, ilu või matkimine - on isikule oluline või mitte. Sümboolne tähendus on mõistel mood üldistusena, mis avaldub moodsuse kui tajuhorisondi kaudu.

Sümbolite tähendused muutuvad ajas - enamasti aeglaselt, ent toimuda võib ka järske muutusi. Toon näiteks mitte rõivastuse, vaid selle esitlemise vormid, traditsioonilise moedemonstratsiooni ja performance'i. Mõistmise muutmine toimub uute seoste loomise kaudu: näiteks püütakse performance'is seda tavaliselt saavutada šokeerimise kaudu. Kui ajalugu käsitleda tõlgendatava ja muudetavana, on võimalik ühe tõlgenduse determineerituse mustrit muuta, kui luua performance'i käigus uus narratiiv. Moedemonstratsioonil esitletakse uut vastanduse kaudu vanale, ent publiku jaoks mõistetavas keeles. Performance loob uue mustri. Performance'it analüüsinud Jeffrey C. Alexander väidab, et rituaal erineb performance'ist. Performance sisaldab samu elemente ja järgneb rituaalile, kuid ei ole sellest välja arenenud (Alexander 2006: 51-62). Tänapäeva performance'is on esinejal isiklik kontakt tekstiga, et tekitada esinedes isiklik kontakt publikuga. Kui etendus toimib, on kõik kaasa tõmmatud. Sotsiaalse ja kultuurilise esituse elemendid ei ole ainult esitaja, publik ja 
misanstseen, vaid ka taustsümbolid (sümbolsüsteemid) ja stsenaarium ning nende kaudu loodavad uued tõlgendused.

Kui püüda näidet moe esitlemisest tõlgendada eri meetoditega, siis mida saab ühe või teise meetodiga näidata ja mida mitte? Moedemonstratsiooni tajume etendusena, kus meile näidatakse moedisaineri loomingut. Publik läheb moeetendusele nagu teatrisse, vahe on žanris ja sõnumi edastamise viisis ning show' elementides. Esitletava moe kultuuriliselt kodeeritud märgid ja esitlemise sekundaarsed keeled toob välja semiootiline analüüs. Performance esitab disaineri mõtte vormistust distantsi vähendades ja mittetraditsioonilistes seostes. Analüüsides strukturalistlikku meetodit kasutades performance'it, mille lavastus edastab sõnumi näiteks moe kui kunsti erilisusest või vastupidi, moe kui prügi olemusest, saab esile tuua varjatud struktuurid, mida etenduses otseselt näha ei ole, ent mille kaudu luuakse uued tähendused. Olgu siinkohal võrdluseks ka hermeneutilise meetodi kasutamine hermeneutika jaoks avaldub tähendus kogemuse sisu kaudu (vt Dilthey 2006), tähenduse mõistmine on eelkõige vaataja poolt disaineri mõtte tõlgendamine. Uurides fenomenoloogilise meetodi abil kogemust, uurime osaleja kogemussisu. Kasutades töövõttena näiteks dialoogi, ei pruugi performance'i uurimine erineda moedemonstratsiooni uurimisest. Dialoogi ette valmistades on oluline, et küsimused annaksid võimaluse kirjeldada subjekti kogemust (Pollio jt 1997: 31). Mida saab fenomenoloogilise meetodi abil näidata, sõltub eesmärgist ja küsimustest, üldiselt seisneb meetod etenduste tähenduste uurimises publiku ja/või etendajate jaoks ja nende analüüsis.

Sümboolse näite ja hüpoteetiliste meetodikasutuste juurest moega seonduvate uurimuste juurde tagasi tulles: moodi on analüüsitud kontekstist ja tähendusest lähtudes. Uurides moodi kui kultuurilist nähtust 20. sajandi Iõpul, toob Melissa Taylor esile, et mood muudab pidevalt oma kohta nii ärilises kui ka kunstilises mõttes, mis on tinginud moe rolli olulisuse ümberhindamise kultuurilises arutelus. Taylori arvates asetseb mood nii kõrg- kui ka popkultuuris kusagil kommertsi ja kunsti vahel ning „kõrgmood” on arenenud pigem kunsti suunas (Taylor 2005). Käsitledes moodi kui kunsti, võib keskenduda nii esteetilistele (Miller 2007) kui ka sotsiaalsetele või psühholoogilistele aspektidele. Sotsioloogide varasemates moekäsitlustes prevaleeris Kanti mõjul matkimise kontseptsioon, Kanti kaasaegne Christian Garve kirjeldas raamatus "Moodidest" aga inimese vajadust vahelduse ja uue järele (Gronow 2001: 92-93). Uurides moodne olla sooviva isiku kogemust psühholoogilisest aspektist, toob Bjørn Schiermer esile moe mõju indiviidi valikutele (Schiermer 2010).

Fenomenoloogiliselt on moodi 21. sajandi alguses uuritud peamiselt tarbimisest lähtudes. Fenomenoloogiline meetod on seega kombineeritud performatiivse strateegiaga, millest lähtuvalt käsitletakse moodi kui praktikat, mis mõjutab harjumusi ja stiili. Mood on moetööstuse produkt (moodsus on müügisõna, sünonüümne uudsega), moe sisu muutub pidevalt, aga moe institutsioonid ei muutu. Näiteks Craig J. Thompsoni ja Diana L. Haytko analüüs 
(Thompson, Haytko 1997) keskendub ajalooliselt kujunenud tähendustele, mida kasutavad tarbijad oma kogemuste tõlgendamiseks ja moe määratlemiseks. Moe ajaloolised tähendused on seotud kultuuritähenduste kujunemise keerulise süsteemiga, mille koodid mõjutavad ka moest kõnelemise konventsionaalseid viise. Nende kaudu on konkreetsed rõivastusküsimused, maitsed ja hoiakud tõlgitud tarbimiskeelde. Uurimuses kasutati töövõttena dialoogi, intervjuude analüüs võimaldas esile tuua mitmesuguseid aspekte intervjueeritavate hoiakute kujunemisel ja tõlgendamisel. Uurimus näitas, kuidas intervjueeritavad lähtusid tõlgendamisel sissekodeeritud viisidest. Thompsoni ja Haytko uurimuse kokkuvõttes tuuakse esile vastandlikud tõlgendused (glamuur ja argisus) ning tõlgenduste aluseks olevad müüdid. Selle uurimuse põhjal järeldavad autorid, et moe fenomen mõjutab tarbijate identiteeditunnetust, adapteerides kultuurilised tähendused nende igapäevaellu ja tekitades kas lihtsustatud arusaamu või kriitilisi tõlgendusi. Uurimuses diskuteeriti paljude eri kontseptsioonidega, ent üldiselt lähtusid uurijad eeldusest, et mood on tarbimispraktika.

Kogemuse fenomenoloogiliseks uurimiseks on suhteliselt tavapäraseks intervjuude ja küsitluste läbiviimine, ent kõik küsitlused ei tähenda veel fenomenoloogilist uurimust - uurimine toimub kogemussisu analüüsides. Teoreetiliste hüpoteeside kinnitamiseks mõeldud vastused ei täida oma eesmärki. Näiteks uuris Dorin Militaru moe mõju elektroonilises kaubanduskeskkonnas ja järeldas, et moe efekt mõjutab oluliselt tarbija käitumist (Militaru 2007). Oma otsustustes lähtub tarbija moe positiivsest tähendusest, mida kasutatakse reklaamides. Moereklaamide loodavaid müüte käsitledes tõi Roman Meinhold filosoofilisantropoloogilisest aspektist välja reklaami põhisõnumi („oled moodne ja ilus ega vanane iial, kui ostad uusi tooteid") ning inimeste uskumuse, et mood täiustab ja uuendab nende elu (Meinhold 2007). Kumbki viimati mainitud uurimustest moekogemust ei ava, sest ei too esile kogemuse subjektiivseid tajuhorisonte. Kogemuse avamist analüüsides selgitab Patrik Aspers erinevaid fenomenoloogilise lähenemise astmeid ja nende filosoofilist alust ning rõhutab, et uurimuse järeldus peab olema tagasiviidav esmavaatele - oluline on subjektiivse perspektiivi läbikumamine. Subjekti „loomuliku suhtumise” esiletoomise kaudu saab kirjeldada, mis on subjekti jaoks tõde, millele toetuvad tema mõtted ja vaated. Uuritav materjal on loomuliku suhtumise sisu. Selle analüüsimine lähtub inimese tähendusstruktuuride mõistmisest, see on esmatasand, mille kaudu on võimalik uurida maailma nii, nagu seda kogetakse (Aspers 2004). Kogemus oma sügavamal tasandil on raskesti ligipääsetav.

Kogemuses ilmneva fenomeni erilise külje esiletoomisel peab Robert Desjarlais parimaks analüüsimeetodiks subjektiivse kogemuse kirjeldust ja rõhutab, et kogemust ei saa käsitleda eraldi fenomenist. Rakendades fenomenoloogilist meetodit antropoloogilises uurimuses, rõhutab Desjarlais, et „kogemuslikkus on kultuuriliselt kujunenud protsess, mis kaasneb maailmas olemisega" (Desjarlais 1996: 73). Kogemuslikkuse kategooria pole mitte eksistentsiaalselt antud, vaid ajalooliselt ja kultuuriliselt kujunenud. Kogemus tugineb millelegi muule 
kui episoodilisele sündmuste järgnevusele ja mõjutab tajumist pidevalt - selles mõttes on ta isikut transformeeriv (samas, 89).

Moe kogemuse kujunemise küsimuse aruteluks pakub võimalust ka Michel Foucault' arheoloogiline meetod. See ei ole fenomenoloogiline ega semiootiline, fookuses ei ole moe kui tähendusliku struktuuri kogemine, vaid kogemussisu kujunemine ajas. Kõik intersubjektiivsed sümbolsüsteemid on kultuurikollektiivi ajalooliseks produktiks, neil on „ajaloolise a priori" (Foucault 2005: 114-115) iseloom, s.t moe kogemust võimaldavad kogemuseelsed struktuurid ei ole universaalsed, vaid ajalooliselt kujunenud. Kui küsimuseks on ajastule omase kogemuse sisu, saab Foucault' meetodi abil esile tuua, milliste faktorite koosmõjul on kujunenud tähendused ja kuidas need mõjutavad praktikat, näiteks, kui me tahaksime põhjalikumalt jälgida muutusi, mis on toimunud 20. sajandi teisel poolel, ja uurida, kuidas need on mõjutanud moodi 21. sajandil konkreetses kultuurikeskkonnas. Võimalik, et sellise uurimuse kaudu ilmneks, et turu poolt üleekspluateeritud mõiste mood ei tähenda aastal 2011 muud kui müügisõna ja moepildis esinevad keerulises koosluses mitmed trendid, mida järgivad eri sotsiaalsed kihid ja subkultuurid.

Fenomenoloogia ei pretendeeri subjektiivsete ja intersubjektiivsete tähenduste põhjuste selgitamisele ja analüüsimisele. Fenomenoloogiline meetod on subjektiivset kogemust uurides orienteeritud kogemuse transtsendentaalse tasandi esiletoomisele. Seda konstateerib Edmund Husserli fenomenoloogilist lähenemist analüüsides ka Dan Zahavi: „[---] fenomenoloogias on tähtis säilitada mõlemat aspekti: huvi subjektiivsuse vastu ja transtsendentaalset perspektiivi" (Zahavi 2008: 686). Analüüsides kirjeldusi esimese isiku perspektiivist, saab esile tuua tähenduste raamistikku ja analüüsida, kuidas kogemus on konstitueeritud.

Husserl, arendades edasi oma intentsionaalsusekäsitlust ja kirjeldades transtsendentaalset reduktsiooni, kirjeldab, kuidas kogemise (cogito) juurde kuulub immanentne pilk objektile, mis lähtub „minast” (Husserl 1993a: 64). Tegemist on sellise tähelepanemise või mõistmisega, mis ei ole mitte kogemise viis üleüldse, vaid erilise aktimoodusega (sks k besonderer Aktmodus), mis on omane teadvusele. „Väärtustamise aktis aga oleme me väärtuse, armastuse aktis armastatu, rõõmu aktis rõõmustava, tegutsemise aktis tegevuse poole pöördunud, ilma kõike seda mõistmata" (samas, 65). Husserli jaoks ei ole väärtust (tõlgendaksin seda kui aktuaalset tähendust) eelnevalt teadvustatult olemas, kogemusele eelnevalt on ainult "tähendushorisondid”. Moodsust kui väärtust kogeme vaates objektile. Arvan, et Husserli mõtet aktimoodusest ja kogemussisust saab arendada selgitamiseks, kuidas tekib moodsus (horisont) subjekti vaatesse ning kuidas mood tähendushorisondina mõjutab vaadet igasugustele objektidele. Sellega on seletatav ka moe fenomen - moe kogemine mõjutab vaateid moele üldisemalt ning sellest lähtuvalt ka moe praktikaid. Moe kogemuse sisu tähendus mõjutab seda, kuidas nähtused meie jaoks ilmnevad. 
Moe kogemust saab hästi kirjeldada ka kultuurivormide mõiste (Viik 2009: 127 jj) kaudu. Kui inimene kirjeldab oma kogemust, kirjeldab ta ilmnevat asja nii, nagu see talle paistab, aga ei kirjelda kultuurivorme, mis kujundavad meie moekogemust. Käsitledes Tõnu Viigi järgi moodi kui üht kultuurivormi, saab esile tuua, kuidas subjektiivsed tähendused moe kogemust mõjutavad. Igapäevases ruumis liikudes me ei näe neid (kultuuri)vorme, vaid seda, kuidas maailm meile (kultuurivormide kaudu) ilmneb. Kirjeldades oma moekogemust, kirjeldame disainerit või suhtumist praegusesse trendi, käsitleme moodi nii, nagu see meile paistab, s.t avaldub meie kogemuses, aga seda kogemust ei kujunda objekt, mis paistab, näiteks ülikond moedemonstratsioonil või foto ajakirjas või silt „moodne” kaupluses.

Kultuurilise kodeerimise käigus luuakse moest hulk narratiive. Need toimivad indiviidi tähendusloome horisontidena, kui kasutada Husserli terminoloogiat, ehk koodidena, kui kasutada Lotmani terminoloogiat. Mood eksisteerib seostes ja detailides, mille tähenduse kaudu võib tõlgendada paljusid objekte. Moodi näeme me lähtuvalt tähendustest, mis eelnevad konkreetsele kogemusele - objekti vaatele, mida me määratleme näiteks kas trendika või vanamoodsana. Seejuures ei mõjuta kultuuriliselt kujunenud tähendused mitte ainult konkreetse objekti kogemist, vaid tajuhorisondina mõjutavad ajastu tunnetamine kultuurilist kogemust üldisemalt. Mood on nähtus, mis on ajastu elutunnetuse ja selle väljendustega vahetult seotud ning võib olla koodiks, mis avab kultuuriliste ilmingute tähendused. See, kuidas me kogeme ümbritsevat kultuuriruumi, avaldub koodide tõlgendamises, ning kui me kultuurivormide kujundatud kodeerimiskeeli tunneme, hoomame kergesti, „mis on õhus”. See aga kujundab meie otsustusi ja hoiakuid, näiteks selgitab, miks me ütleme täna millegi kohta, et see on cool.

Kokkuvõtteks võiks öelda, et mood, mida distsipliinina käsitleti traditsiooniliselt osana ajaloost või kunstiajaloost, on seoses humanitaarteaduste arenguga saanud uueks uurimisobjektiks. Semiootiliselt uuritakse tähendusi kui seoseid, mille kaudu me näeme objekti lähtuvalt tähendusstruktuuridest; fenomenoloogiliselt saab uurida konkreetse kogemuse struktuuri eesmärgiga tuua välja subjektiivse tähendusloome transtsendentaalsed mehhanismid. Fenomenoloogilise meetodi abil saab selgitada, kuidas moe kogemuse tähendus tajuhorisondina mõjutab (ajastu tunnetamisega seotud) kultuurilist kogemust üldisemalt.

\section{Ki r ja n d u s}

Alapack, Richard J. 2009. The Epiphany of Female Flesh: A Phenomenological Hermeneutic of Popular Fashion. - The Journal of Popular Culture, Vol. 46, No. 6, Ik 977-1003.

Alexander, Jeffrey C. 2006. Cultural Paradigmatics: Social Performance between Ritual and Strategy. - Social Performance. Eds. J. C. Alexander, B. Giesen, J. L. Mast. New York: Cambridge University Press, Ik 29-90. 
Aspers, Patrik 2004. Empirical Phenomenology: An Approach for Qualitive Research. - London School of Economics and Political science, Papers in Social Research methods, Qualitative Series, No. 9, Ik 1-15.

Aspers, Patrik 2001. Markets in fashion: a phenomenological approach. Stockholm: City University Press.

Barthes, Roland 1990. The fashion system. Berkeley: University of California Press.

Benjamin, Walter 2010. Valik esseid. (Loomingu Raamatukogu 26/29). Tallinn: Perioodika.

Black, Prudence. 2009. The detail: Setting Fashion Systems in Motion. - Fashion Theory: the Journal of Dress, Body \& Culture, Vol. 13, Ik 499-510.

Burke, Peter 2006. Kultuuride kohtumine. Tallinn: Varrak.

Desjarlais, Robert 1996. Struggling Along. - Things as They Are: New Directions in Phenomenological Anthropology. Ed. M. Jackson. Bloomington and Indianapolis: Indiana University Press, Ik 70-93.

Dilthey, Wilhelm 2006. Teiste isikute ja nende eluavalduste mõistmine. - Akadeemia, nr 8 , Ik 1779-1796.

Flusser, Vilém 1984. Towards a Philosophy of Photography. Göttingen: European Photography Publishers.

Foucault, Michel 2005. Teadmiste arheoloogia. Tartu: Tartu Ülikooli Kirjastus.

Geertz, Clifford 1990. Religioon kui kultuurisüsteem. - Akadeemia, nr 11, Ik 2031-2328.

Husserl, Edmund 1993a. Ideen zu einer Phänomenologie und phänomenologischen Philososophie: Allgemeine Einführung in die reine Phänomenologie. Tübingen: Niemeyer.

Husserl, Edmund 1993b. Logische Untersuchungen. Tübingen: Niemeyer.

Husserl, Edmund 1995. Cartesianische Meditationes: Eine Einleitung in die Phenomenologie. Hamburg: Meiner.

Gronow, Jukka 2001. Taste and Fashion: The Social Function of Fashion and Style. - Acta Sociologica, No. 36, Ik 89-100.

Kawamura, Yuniya 2005. Fashion-ology. An Introduction to Fashion Studies. New York: Berg.

Kopnina, Helen. 2007. The World According to Vogue: The Role of Culture(s) in International Fashion Magazines. - Dialectical Anthropology, No. 31, Ik 363-381.

Lotman, Juri 1999. Kultuurisemiootika. Tallinn: Olion.

Lotman, Juri 2003. Vestlusi vene kultuurist, 1. Tallinn: Tänapäev.

Lotman, Juri 2006. Kunstilise teksti struktuur. Tallinn: Tänapäev.

Lurie, Alison 1983. The Language of Clothes. London: Hamlyn.

Meinhold, Roman 2007. Meta-Goods in Fashion-Myths. Philosophic-Anthropological Implications of Fashion Advertisements. Lecture at the Graduate School of Philosophy and Religion Assumption University of Thailand in Bangkok. - http://www.roman-meinholds.com (11.11.2011).

Militaru, Dorin 2007. A Framework for Defining Fashion Effect in Electronic Commerce Environments. - E-Commerce and Web Technologies: 8th international conference. Eds. G. Psalia, R. R. Vagner, Ik 201-211.

Miller, Sanda 2007. Fashion as Art; is Fashion Art? - Fashion Theory: The Journal of Dress, Body \& Culture, Vol. 11. Ik 25-40. 
Polhemus, Ted 1996. Style Surfing: What to Wear in the 3rd Millennium. Thames \& Hudson.

Pollio, Howard R., Tracy B. Henley, Craig J. Thompson 1997. Dialogue as a Method: The Phenomenological Interview. - The Phenomenology of Everday Life. Cambridge, UK: Cambridge University Press, Ik 28-56.

Schiermer, Bjørn 2010. Fashion Victims: On the Individualizing and De-individualizing Powers of Fashion. - Fashion Theory: The Journal of Dress, Body \& Culture, Vol. 14. Ik 83-104.

Simmel, George 1904. Fashion. - International Quartely, No. 10, Ik 130-155 - http://www. modeteorie.de (11.11.2011).

Simmel, George 2006. Simmel on culture: selected writings. Eds. D. Frisby, M. Featherstone. London: Sage.

Zahavi, Dan 2003. Husserl's phenomenology. Stanford: Stanford University Press.

Zahavi, Dan 2008. Phenomenology. - Routledge Companion to Twentieth-Century Philosophy. Ed. D. Moran. London, New York: Routledge, Ik 661-692.

Tamm, Marek 2008. Quo vadis, humaniora? - Keel ja Kirjandus, nr 8-9, Ik 577-588.

Taylor, Melissa 2005. Culture Transition: Fashion's Cultural Dialogue between Commerce and Art. Fashion Theory: the Journal of Dress, Body \& Culture, Vol. 9. Ik 445-460.

Thompson, Craig J., Diana L. Haytko 1997. Speaking of Fashion: Consumers' Uses of Fashion Discourses and the Appropriation of Countervailing Cultural Meanings. - Journal of Consumer Research, Vol. 24, Ik 15-42.

Viik, Tõnu 2008. Kultuuriline pööre. - Keel ja Kirjandus, nr 8-9, Ik 604-616.

Viik, Tõnu 2009. Kolm teesi kultuurivormide loomuse kohta. - Vikerkaar, nr 1-2, Ik 127-137.

Ines Piibeleht - Eesti Muusika- ja Teatriakadeemia kultuurikorralduse ja humanitaarainete osakonna lektor. Aastal 2009 astus Tallinna Ülikooli Humanitaarinstituudi filosoofiateaduskonna doktoriõppesse, teemaks kultuuri tähendusloome uurimine moe kogemuse dünaamiliste protsesside kaudu. Aastal 2011 alustas ta empiirilise uurimuse läbiviimist eesmärgiga selgitada moe kogemuse kujunemist.

E-post: ines.piibeleht@gmail.com 


\title{
The Phenomenon of Fashion
}

\author{
Sum mary
}

Since the last quarter of the 20th century, particularly after the "cultural turn", the interest in fashion has been increasing in a variety of different disciplines. Fashion has begun to be investigated in many different contexts, using new theoretical approaches. Fashion can be regarded as a social phenomenon, a sign system, as art, myth, or the product of the fashion industry. The purpose of this article is not to provide a definition of fashion, but rather to raise the question of how to approach the experience of fashion analytically. The methodological issues discussed here emerged in the course of preparing for empirical research on fashion. The observations and comparisons that constitute the core of this article are the result of efforts to juxtapose different methods. The traditional history of fashion used a historical-epistemological strategy but, depending on how one defines culture, the meaning of fashion can also be analysed using methods based on different epistemological strategies. The phenomenological method elaborated by Edmund Husserl, which I have chosen for my analysis of the experience of fashion, defines culture through the experiential acts of individuals. Simply stated, phenomenology considers the world as it is given to us in our consciousness. What is most important for empirical research is that the phenomenological method makes it possible to study the structure of a concrete experience and to focus on the mechanisms of the subjective creation of meaning. Thus this article has two main foci: a theoretical analysis of how the experience of fashion can be analytically revealed using the phenomenological method, and a comparison of the phenomenological approach with methods based on other strategies.

The analysis of descriptions in the first person makes it possible to highlight how experience has been constructed. People "see" fashion based on structures of meaning; when they describe their own experience, they describe the object as it appears to them. The experiential act acquires content as mediated through meaning, even though the structures of consciousness that lead to the experience are not expressed explicitly through specific experiential content. Referring to Husserl and distinguishing between the mode of appearance of an object and the apparent object, it is possible to draw attention to the way a fashion image appears to an individual, and to describe how changes take place in the content of the experiential act. No other epistemology allows for the analysis of a change in perception in relation to the same object. As the content of experience changes, so does the look, which in turn alters and influences the next experience. All intentional objects toward which our consciousness is directed are shaped throughout the process of experiencing them. We experience objects, see the form of these objects and their connections to design, their use of language, and a variety of other contexts characteristic of the era. Awareness of fashion develops in the course of experience, which in turn influences the content of subsequent experience. The experience of fashion is not something static, but a continuous process.

Phenomenology does not purport to explain and analyse the reasons behind subjective and intersubjective meanings, but is rather oriented toward calling attention to the transcendental level of experience. With the help of narratives generated in the course of cultural coding, the objects we see on the (fashion) field have formed their specific horizons of meaning creation. As a code in cultural and social space which 
opens the meanings of cultural phenomena, fashion influences the perception of the "self" and the object of concrete experience, as well as exerting a broader influence on the content of experience by means of a horizon of meaning. It is possible to develop Husserl's idea of the mode of the act and the content of experience in order to explain the creation of fashionability as a horizon for the subject's look, and how, as a horizon of meaning, fashion influences the subject's perspective on objects of all kinds. This, in turn, allows for the explanation of how the meaning of the content of the fashion experience influences the perception of a particular era.

Ines Piibeleht - Lecturer at the Cultural Management and Humanities Department of the Estonian Academy of Music and Theatre. In 2009 she started her doctoral studies at the Faculty of Philosophy of the Estonian Institute of Humanities at the Tallinn University on the subject of the study of culture-dependent processes of meaning creation. In 2011 she started an empirical material-based study aiming at the revealing of the structures of consciousness that allow the experiencing of fashion.

E-mail: ines.piibeleht@gmail.com 